\title{
A memetic algorithm for location-routing problem with time windows for the attention of seismic disasters: a case study from Bucaramanga, Colombia
}

\section{Un algoritmo memético para el problema de localización- ruteo con ventanas de tiempo para la atención de desastres sísmicos: un caso de estudio de Bucaramanga, Colombia}

http://dx.doi.org/10.17981/ingecuc.14.1.2018.7

Research Article. Submission Date:12/01/2018. Accepted: 01/05/2018

\author{
Henry Lamos Díaz \\ Universidad Industrial de Santander, Grupo de Investigación OPALO. Bucaramanga (Colombia). \\ hlamos@uis.edu.co \\ Karin Aguilar Imitola \\ Universidad Industrial de Santander, Grupo de Investigación OPALO. Bucaramanga (Colombia). \\ karin.aguilar@correo.uis.edu.co \\ Melissa Andrea Barreto Robles \\ Universidad Industrial de Santander, Grupo de Investigación OPALO. Bucaramanga (Colombia). \\ melissa.barreto@correo.uis.edu.co \\ Paula Nathalia Niño Niño \\ Universidad Industrial de Santander, Grupo de Investigación OPALO. Bucaramanga (Colombia). \\ paula.nino@correo.uis.edu.co \\ Daniel Orlando Martínez Quezada \\ Universidad Industrial de Santander, Grupo de Investigación OPALO. Bucaramanga (Colombia). \\ daniel.martinez5@correo.uis.edu.co
}

Para citar este artículo:

H. Lamos Díaz, K. Aguilar Imitola, M. A. Barreto Robles, P. N. Niño Niño \& D. O. Martínez Quezada, "A memetic algorithm for locationrouting problem with time windows for the attention of seismic disasters: a case study from Bucaramanga, Colombia," INGE CUC, vol. 14, no. 1, pp. $75-86,2018$. DOI: http://doi.org/10.17981/ingecuc.14.1.2018.7

\begin{abstract}
Introduction- In recent years, a great part of the population has been affected by natural and man-caused disasters. Hence, evacuation planning has an important role in the reduction of the number of victims during a natural disaster.

Objective- In order to contribute to current studies of operations research in disaster management, this paper addresses evacuation planning of urban areas by using buses to pick up affected people after an earthquake.

Methodology- The situation is modeled using Location-Routing Problem with Time Windows (LRPTW) to locate emergency shelters and identify evacuation routes that meet attention time constraints. To solve the LRPTW problem, a memetic algorithm (MA) is designed to minimize the total response time during an evacuation. The algorithm is not only validated using instances of literature, but also with the assessment of a case study of a seismic event in Bucaramanga, Colombia.

Results and conclusions- The main contribution of this article is the development of a memetic algorithm for the solution of the proposed model that allows to solve real-size instances. The hybrid initialization of the MA prevents an early convergence by combining randomness and a heuristic technique. Computational results indicate that the MA is a viable approach for the LRPTW solution. Likewise, a case study is presented for the city of Bucaramanga in order to validate the proposed model. Two scenarios are simulated showing that the management of the time windows (homogeneous or random) directly influences the solution and affects the objective function. From a practical perspective, the location-routing problem must consider other criteria such as the cost of evacuation, including the attention delay cost, and the cost of opening shelters and routing.
\end{abstract}

Keywords- Humanitarian logistics, evacuation, earthquake, location-routing problem (LRP), time windows, memetic algorithm

\section{Resumen}

Introducción- En años recientes gran parte de la población ha sido afectada por desastres tanto naturales como antrópicos. Por esto, la planificación de la evacuación juega un papel importante en la reducción del número de víctimas ante un desastre natural.

Objetivo-Con el propósito de contribuir a los estudios actuales desde la investigación de operaciones en gestión de desastres, esta investigación aborda la planificación de la evacuación de áreas urbanas usando buses para recoger afectados.

Metodología- El problema se modela mediante un problema de localización-ruteo con ventanas de tiempo (LRPTW) para determinar el número y la ubicación de los albergues las y rutas de recolección para evacuación, cumpliendo restricciones en tiempo de atención. Para solucionar el LRPTW, se diseña un algoritmo memético (MA) que minimiza el tiempo total de respuesta en la evacuación. El algoritmo es validado en instancias de la literatura y mediante un caso de estudio de un evento sísmico en Bucaramanga (Colombia).

Resultados y conclusiones- La contribución principal de este artículo es el desarrollo de un MA para solucionar el modelo propuesto, que permite resolver instancias de tamaño real. La inicialización híbrida del MA evita una convergencia temprana, combinando aleatoriedad con una técnica heurística. Los resultados computacionales indican que el MA es un enfoque viable para solucionar el LRPTW. Así mismo, se presenta un caso de estudio en Bucaramanga para validar el modelo propuesto. Se plantean dos escenarios de desastre, evidenciando que el tratamiento que se da a las ventanas de tiempo (homogénea o aleatoria) influye directamente en la solución y afecta la función objetivo. Desde un enfoque práctico, el problema debe considerar otros criterios que pueden influir en la planificación de la evacuación, como el costo de la evacuación, costo de la demora en la atención, costo de apertura y de ruteo.

Palabras clave-Logística humanitaria, evacuación, terremoto, problema de localización-ruteo, ventanas de tiempo, algoritmo memético 


\section{INTRODUCTION}

Recently, urban population growth, lack of construction planning, and climate change have led to an increasing exposure to disasters. The human and economic costs of disasters around the world are shocking. In the last 20 years, more than 4 billion people have been affected by natural disasters around the world. In turn, they have generated losses of more than US\$2000 billion [1]. In this context, disaster management is essential.

Disaster management can be defined as a set of processes implemented in order to manage disasters before, during, and after they occur to prevent or mitigate their effects. Regardless of the nature of the event, the disaster management cycle consists of four main phases: mitigation, preparedness, response, and recovery. The first two processes are performed prior to the disruptive event so as to reduce the effects. Whereas the latter take place after the occurrence of a disaster to meet the basic needs of the population in the short term and achieve their complete rehabilitation in the long term [2]. Each phase requires complex operations. FEMA [3], Altay and Green [4], Anaya-Arenas et al. [5] present the main activities that each phase involves.

In this sense, humanitarian logistics have attracted the attention of the Operations Research and Management Science (OR/MS), both in the academic and professional communities. On the one hand, Altay and Green (2006) [4] identify OR/MS contributions to disaster management and indicate an interest in developing agile logistical systems to address different types of disasters in order to increase efficiency and effectiveness of responses and decrease its impacts.

In turn, Galindo and Batta [6] large affected populations and serious environmental damages. Given these devastating effects, there is an increasing interest in developing measures in order to diminish the possible impact of disasters, which gave rise to the field of disaster operations management (DOM evaluate how the gaps identified by Altay and Green [4] have been covered. On the other hand, Kovács and Spens [7] draw a parallel between humanitarian logistics and commercial logistics. Simpson and Hancock [8] cover OR literature in the emergency response phase from 1965 to 2007. De la Torre, Dolinskaya, and Smilowitz [9] focus on the literature of problems related to vehicle routing to deliver goods and services in regions affected by a disaster. Caunhye, Nie, and Pokharel [10] divide the literature of emergency logistics into three types of problems: location of services, distribution of aid and transport of victims, and other operations.

Within humanitarian logistics, evacuation planning is critical for urban emergency preparedness. It involves the determination of the quantity and location of shelters, the location of meeting points, and the identification of evacuation routes. In most cases, the evacuation process is carried out by foot; however, there is a possibility to pick up people in the meeting points in vehicles to take them safely to the shelters.

The operations research literature for evacuation management is relatively scarce. Regarding urban evacuation, Yamada [11] solved a shortest path problem and a minimum-cost flow problem to assign residents to refuges within an evacuation plan. Lu, George, and Shekhar [12] presented a heuristic algorithm named Capacity Constrained Route Planner (CCRP) to solve the evacuation planning problem, whose formulation used a static network with timedependent node capacity and edge capacity. Chiu et al [13] presented a model for no-notice mass evacuation through a transformation approach of a typical transportation planning network to an evacuation network configuration. Sayyady and Eksioglu [14] proposed a methodology to design plans for evacuating transit-dependent citizens during no-notice disasters. The problem is modeled by mixed-integer linear programming and sought to minimize the total evacuation time and the number of casualties. In 2011, Bish [15] introduced a model for bus-based evacuation planning known as Bus Evacuation Problem BEP, along with two mathematical programming formulations to develop a heuristic algorithm. Recently, Goerigk, Grün, and Hebler [16] addressed the bus evacuation problem (BEP) by means of describing multiple approaches to find both lower and upper bounds, and apply them in a branch and bound framework. Bish, Sherali, and Hobeika [17] used a mixed-integer programming model that accounted for evacuation dynamics and congestion in order to study demand-based strategies for evacuation planning. Goerigk and Grün [18] present a robust formulation of BEP (RBEP) in which the number of evacuees is uncertain, but a set of possible scenarios is known. Recently, Goerigk, Grün and Hebler [19] introduced an IBEP: a model that integrates the location of the collection points for evacuees and shelters with the programming of the bus fleet to improve the evacuation time.

Location Routing Problem (LRP), a problem related to the BEP, includes the decisions of locating facilities and vehicle routing, which are relevant in the planning of the evacuation and the determination of location of meeting points and shelters, as well as the routes to be used to pick up the evacuees. In different distribution systems, these two problems are treated independently, obtaining low quality solutions [20].

In the LRP, these two decisions are considered interdependently. That is, how many and which facilities must be opened and which routes must be built to satisfy client demand. This implies that two combinatorial problems must be solved. The first one is based on the Facility Location Problem (FLP) and the other one is developed with the fundamentals of Vehicle Routing Problem (VRP). 
Recently, multiple literature reviews on LRP have been published [21]-[24]. Although most LRP applications have been focused on goods distribution [25], [26], there are other application areas that suggest interesting variants [27]-[29] with particular optimization criteria, like disaster management. The LRP has been applied for decision-making in humanitarian logistics in various natural disasters. Logistic operations include coordination and transportation of goods and wounded people [30] medical materials and personnel, specialised rescue equipment and rescue teams, food, etc., victims' search and rescue [31], debris removal and final disposal site location [32], and supplies location and pre-positioning [33]-[36]. Most researches on LRP for evacuation planning comprise more than one objective, including the reduction of the evacuation time, the minimization of costs associated with the opening of shelters and transportation [37], and the risk related to routes or facilities [38]-[40].

Since LRP is an NP-hard problem [23], it is difficult to solve computationally as the number of variables of the model increases (for example, the number of clients to be attended or the quantity of facilities to be located). In humanitarian logistics, the initial response must be received immediately and any violation of time constraints can cause suffering and losses, so it must be penalized in a planning and decision-making process.

An LRP where the service should be initiated with a client during a pre-established time interval and specified by the client is called location routing problem with time windows (LRPTW) and it is created in commercial logistics. Although time window restrictions have been studied extensively for vehicle routing problem (VRPTW), these constraints have not received the same attention in the context of the LRP. Nikbakhsh and Zegordi [41] present a Two-Echelon Location-Routing with Soft Time Window Constraints (2E-LRPTW), which set forth a heuristic for the construction of a solution improved by an Or-opt procedure. Gündüz [42] combines a capacitated facilities location problem (CFLP) and a VRPTW that generate a single-stage LRP with time windows (SSLRPTW). It considers capacity constraints in deposits and clients, and proposes a tabu search algorithm to solve the problem. Fazel, Hemmati, Davari and Turksen [43] suggest an LRPTW under uncertainty, and assume that demand and travel times are fuzzy variables, so a simulated annealing algorithm is presented as a solution method.

In recent years, researchers have included time constraints as part of evacuation planning by using hybrid metaheuristics as solution methods. Song et al [44] formulated an LRP with time windows (LRPTW) for an evacuation plan in a natural disaster and they used a hybrid genetic algorithm to minimize the total evacuation time. Li and Zhou [31] established a model of fuzzy rescue time LRPTW for the optimization of boat routes and the location of shelters in the search of victims of flood disasters. To solve the model, a hybrid genetic algorithm was designed and its results indicate that the model and the algorithm provide a method for victim search decision-making in flood disasters. Goerigk, Deghdak, and Heßler [40] proposed a multi-criteria optimization model and developed a genetic algorithm of NSGA-II type to solve the problem heuristically to determine the location and number of shelters and vehicle route arrangement to pick up evacuees in a way that the total evacuation time and the evacuees' exposure to risks could be minimized. Govindan et al [25] addressed a two-echelon LRP with time windows (2E-LRPTW) to determine the number and the location of facilities as well as to optimize the amount of products delivered. They proposed a hybrid of two multi-objective algorithms: multiobjective particle swarm optimization (MOPSO) and adapted multi-objective variable neighborhood search (AMOVNS), which aim to reduce costs caused by carbon footprint and greenhouse gas emissions throughout the network.

The integration of public transport and the location of shelters are areas of active research [24]. Therefore, the main contribution of this paper is to provide a model for evacuation planning in earthquake disasters, considering (a) the location of meeting points and the design of bus-based evacuation routes; (b) the implementation of a real network using a geographic information system (GIS); (c) the standard response time limitations (72 hours after the occurrence of the disruptive event); and (d) the application of the proposed model through a case study.

In this paper, a location-routing problem with time windows (LRPTW) is presented to minimize the total evacuation time. The problem network is represented by Google Maps and the model is solved by a memetic algorithm that integrates a genetic algorithm and three improvement movements as a local search procedure. The proposed algorithm is validated through literature instances. For the implementation of the proposed model, a seismic hazard scenario is designed for Bucaramanga (Colombia), a city located 50 kilometers from one of the most active seismic nests in the world.

This paper is organized as follows: section 2 describes the evacuation problem as well as its mathematical formulation; section 3 presents the proposed algorithm for the LRPTW solution; section 4 describes the computational results for the algorithm; section 5 shows the case study; and section 6 presents the conclusions of the paper. 


\section{Problem Statement and Model Formulation}

Vehicle evacuation is modeled using the locationrouting problem with time windows (LRPTW). A time window corresponds to the period in which a route must visit a location in the distribution network. The time window is considered as hard if the vehicle visits the client very early and it is allowed to wait until the service start. However, it is not allowed to arrive after the service has started. In contrast, the time window is soft if the service time constraint can be violated at a defined cost. In this paper, we use hard time windows for the temporary space of picking up the affected people in order to assign a vulnerability measure for each affected zone and also to consider the planning horizon constraint for evacuation and rescue operations (72 hours).

Our mathematical model for the LRPTW is based on the one proposed by $\mathrm{Zhu}$ et al [45] with a variation in the objective function. While these authors aim to minimize the total cost, this research seeks to minimize the total evacuation time. The network for the problem can be defined as follows: the network $G(S, A)$ is a complete graph where $S=R \cup J$ is the set of all nodes, $R$ is the set of possible shelters to open, and $J$ are the possible meeting points (MP). The set $\mathrm{A}=\{(\mathrm{i}, \mathrm{j}): \mathrm{i}, \mathrm{j} \in \mathrm{S}\}$ represents the road connections between the nodes (edges). Each edge $(i, j)$ has a non-negative cost $t_{i j}$ that corresponds to the time of driving from node $i$ to node $j$. Each node (shelter) $r \in R$ has a capacity $Q_{r}$ that represents the number of people that can be hosted. Each $\mathrm{MP} j \in J$ has a $q_{j}$ demand that represents the number of people who need to be carried by bus to the shelter. A limited number of homogeneous buses $k \in V$ with known capacity $C$ are available at each shelter. In addition, $u_{l k}$ is an auxiliary variable for cycle elimination purposes; $a_{i}$ and $b_{i}$ are the earliest and the latest times for the MP to accept the service, respectively; $w_{i}$ is the service starting time, which is required to lie in the interval $\left[a_{i}, b_{i}\right]$; and is the length of service.

The problem is to determine which meeting points (MP) will be enabled for picking up the victims, the allocation of these points to the shelters, and the evacuation route that minimizes the total evacuation time. The above is subject to the following assumptions:

- Each MP is served by a single bus once.

- The total demand of the MP assigned to a shelter cannot exceed its capacity, and this demand is known.

- Each route starts and ends in the same shelter.

- Each MP is connected to its shelter by a route.

- A route is served by a single bus, and the bus capacity cannot be exceeded.

- The set of potential shelters is known.

The decision variables and parameters of the mathematical model are defined as follows:

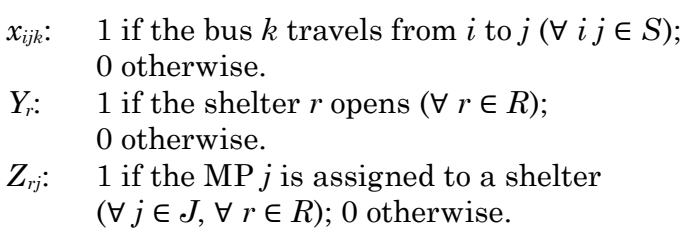

The following is the mathematical formulation:

$$
\begin{aligned}
& \min \sum_{i \in S} \sum_{j \in S} \sum_{k \in V} t_{i j} x_{i j k} \\
& \text { s.t: } \\
& \sum_{k \in V} \sum_{i \in S} x_{i j k}=1 \forall j \in J ; i \neq j ; \\
& \sum_{j \in J} q_{j} \sum_{i \in S} x_{i j k} \leq C \forall k \in V ; i \neq j ; \\
& \sum_{k \in V} \sum_{j \in J} q_{j} \sum_{i \in S} x_{i j k} \leq Q_{r} Y_{r} \forall r \in R ; \\
& \sum_{p \in S} x_{i p k}-\sum_{p \in S} x_{p j k}=0 \forall k \in V ; i, j \in S ; i \neq j ; \\
& \sum_{r \in R} \sum_{j \in J} x_{r j k} \leq 1 \forall k \in V ; \\
& \sum_{l \in J}\left(x_{r l k}+x_{l j k}\right) \leq 1+Z Z_{r j} \forall r \in R ; j \in S ; k \in V ; \\
& \sum_{j \in J} x_{r j k} \leq Y_{r} \forall k \in V ; r \in R ; \\
& a_{i} \leq w_{i} \leq b_{i} \forall i \in J ; \\
& w_{i}+t_{i j}+s_{i}-w_{j} \leq M\left(1-x_{i j k}\right) \forall i, j \in J ; k \in V ; i \neq j ; \\
& u_{l k}-u_{j k}+N x_{l j k} \leq N-1 \forall j, l \in J ; k \in V \\
& u_{l k} \geq 0 \forall l \in J ; k \in V ; \\
& \sum_{i \in S} x_{i i k}=0 \forall \mathrm{k} \in \mathrm{V} ; \\
& \sum_{k \in V} x_{r l k}+Y r+Y \leq 2 \forall r \in R ; l \in R ;
\end{aligned}
$$

In addition to the constraints proposed by Zhu et al [45], we consider:

$$
\sum_{j \in J} q_{j} \leq \sum_{r \in R} Q_{r} Y_{r}
$$

In the model above, the objective function (1) minimizes the total evacuation time. Constraint (2) guarantees that each MP is assigned to a bus route. Constraints (3) and (4) refer to capacities. Constraint (3) ensures that the bus capacity is not exceeded by the demand of the MPs assigned to the route, and (4) indicates that MPs assigned to a shelter do not exceed its capacity. Constraint (5) ensures the continuity of the routes, forcing each vehicle to enter and leave each visited node. Constraint (6) indicates each bus begins from the assigned shelter. Constraint (7) ensures that each shelter only serves the MP assigned to it. Constraint (8) ensures that MPs are assigned to a single shelter. The set of equations (9) - (10) enforces the time windows cannot be violated (given as a big number). Equations (11) - (12) are constrains of sub-tours and auxiliary variable respectively. Constraint (13) ensures that the bus travels from a node $i$ to $j$. Constraint (14) states that there are no routes between any shelters. Finally, constraint (15) ensures that the total capacity of all open shelters is greater than or equal to the demand of total MPs in order to satisfy the total demand. 


\section{III.Memetic Algorithm to Solve the Lrptw}

Considering that LRP is an NP-hard problem [23], heuristic methods are best suited to obtain feasible solutions in large instances quickly. Therefore, this research proposes a memetic algorithm (MA), since it combines evolutionary algorithm methods with local search methods in order to take advantage of the implicit strategies of each approach.

\section{A. Generation of initial population}

An encoding with natural numbers is used to present the solutions of the algorithm. Each individual in the population consists of three sub-chains: the shelter status, the assignment of MPs to the open shelters, and the bus routes for each shelter. The first subchain is a binary mask corresponding to the shelters' state, where the value of the gene in the $i$ - $t h$ position indicates whether the shelter $i$ is open (value of 1 ) or closed (value of 0 ). This sub-chain is randomly generated verifying that a minimum number of shelters are enabled in the solution to satisfy the demand. From the sub-chain of the shelters' status, a second sub-chain is generated; it corresponds to the assignment of MPs to the open shelters. This second sub-chain is a permutation with repetition, where the value of the gene in the $j$ - $t h$ position indicates the shelter to which the MP $j$ has been assigned. To carry out the allocation, the nearest neighbor heuristic is used for the enabled shelters, avoiding the violation of capacity constraint and the assignment of distant MPs to a shelter, as well as creating the sequences of visits. The routes generated in each solution are stored in the last sub-chain. Fig. 1 shows an example of the initial solution encoding.

The procedure for generating a chromosome is repeated until the size $N$ of the population $P_{t}$ is complete. $N$ represents the number of individuals in the population and $t=\{1,2,3 \ldots\}$ is the set of generations, with $t=0$ for the initial population $P_{0}$.

The pseudocode of the procedure for the generation of an initial solution is presented in Algorithm 1.

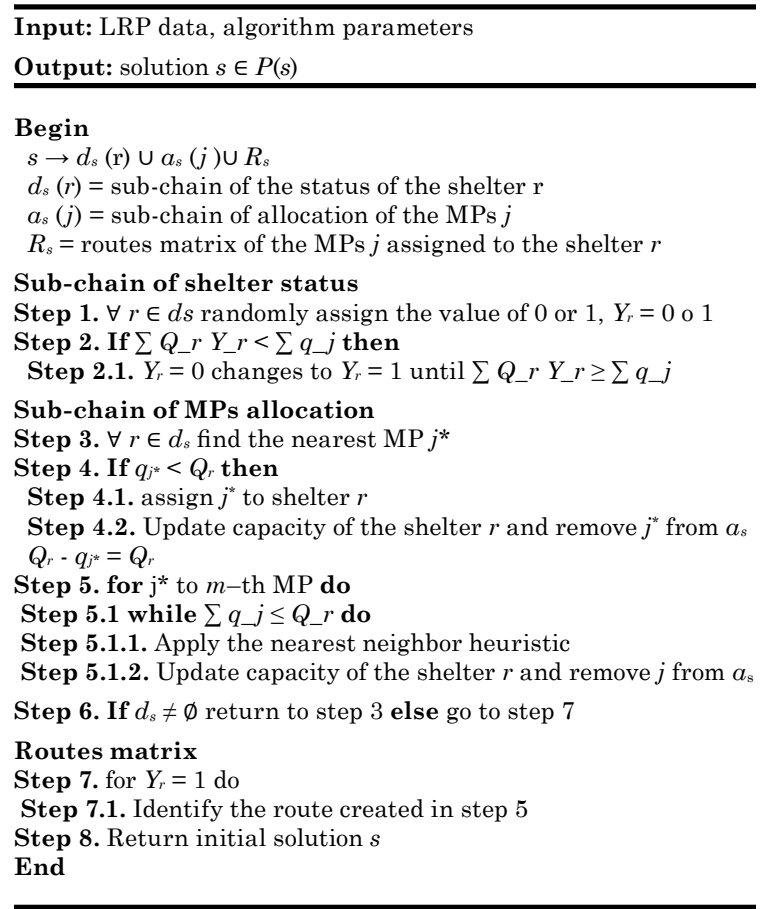

Alg 1. Algorithm to generate an initial feasible solution. Source: Authors.

\section{B. Evaluation of the objective function}

An aptitude value is assigned to each individual of the population. In this work, two scenarios were considered: in the first one the aptitude function corresponds to the evacuation time and it is calculated according to the travel time between shelters and meeting points of the longest or most time-consuming route; that is, when the last bus arrives with evacuees to its shelter. In the second scenario the aptitude function is defined as the summation of all travel times of each route. The first aptitude function scenario was used for the case study and the second was used for the validation of algorithm consistency.

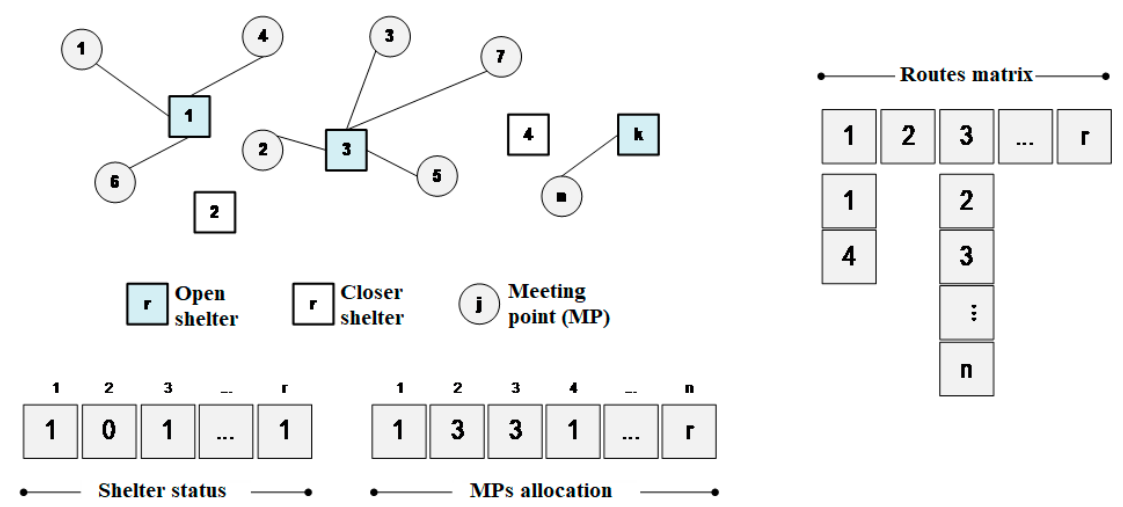

Fig 1. Population encoding scheme. Source: Authors. 


\section{Selection, crossover and mutation operators}

In order to determine which individuals will be chosen for reproduction, the method of probabilistic tournament selection by comparing the value of the objective function is selected. With it, the chosen individuals will be part of the solution pool. Given two individuals of the pool, two new solutions are generated through information exchange in the routes sub-chain. A specific crossover of non-binary encoding is used in which two shelters of an individual previously selected to be reproduced are chosen randomly, then the first route of each shelter is exchanged. The best individuals, both parents and children, get in the solution pool. Each solution in the pool is mutated by the swap operator. Two MPs that belong to different routes are randomly chosen and they are exchanged.

The crossover and mutation operators can generate non-feasible solutions, so after using each operator, the feasibility of the solution must be verified in compliance with the model constraints. This verification is performed, considering:

If $\sum_{k \in V} \sum_{i \in S} x_{i j k}=0$, the first closed shelter in the solution is enabled, changing the value from 0 to 1 in the first sub-chain.

If $\sum_{k \in V} \sum_{j \in J} C x_{r j k}>Q_{r}$, the last MP assigned to the shelter is removed and it is re-assigned to the first open shelter with sufficient capacity. If any shelter has the capacity to receive the MP, one of the closest shelters is randomly enabled.

Finally, if constraints (9) - (11) are not met, a MP is extracted from the shelter route and assigned to another route where the time window is fulfilled for this MP.

\section{Local search}

In each generation of MA, a heuristic procedure is implemented as a local search algorithm to improve the offspring obtained by genetic operators. In this case, we implement the neighborhood operator CustMove, proposed by Karaoglan \& Altiparmak in 2015 [46] for capacitated location-routing problem with mixed backhauls (CLRPMB). The CustMove operator consists of the random selection of a MP that removes it from its current position and inserts it in the best position of the same route or different route that belongs to the same shelter or different shelter. An illustrative example for this operator can be seen in Fig. 2. In this figure, customer 10 is removed from its current position (Fig. 2a) and inserted to the third position of route (1-9-8-4-1-6) (Fig. 2b). When MPs belong to routes in different shelters, it must be verified that the insertion in the other route is possible without violating their capacity or that of the shelter.

The pseudocode of the proposed MA is presented in Algorithm 2.

Procedure: Memetic algorithm for the LRPTW

Input: LRP data, algorithm parameters

Output: best solution $\mathrm{s}^{*}$

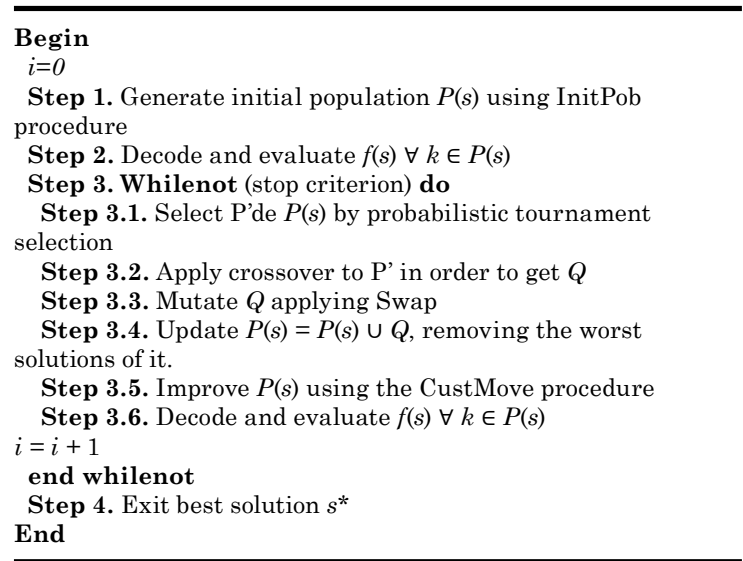

Alg 2. Pseudocode of the MA general procedure. Source: Authors.
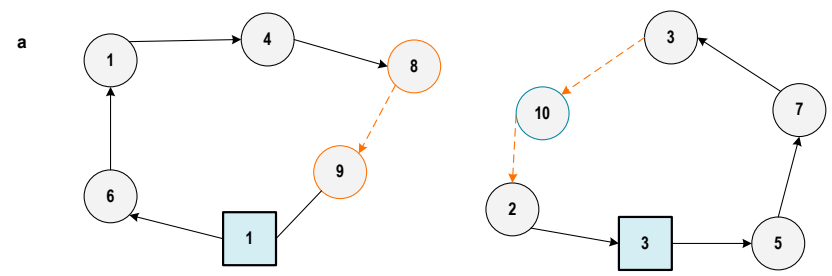

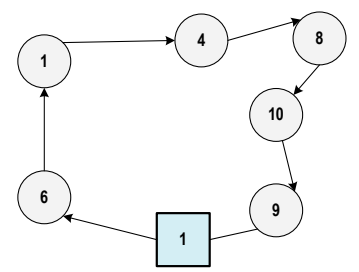

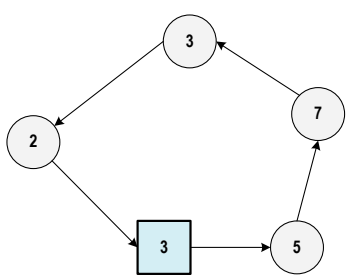

Fig 2. Procedure of the neighborhood operator CustMove. Source: Karaoglan \& Altiparmak [46]. 


\section{Computational Results}

\section{MA performance in CLRP (Capacitated Location- Routing Problem) instances}

During the development of this research, there were no established instances for the LRPTW to verify the consistency of any particular solution method. However, to validate the consistency of the proposed algorithm, we use the Prodhon [47] test library for the CLRP, since its instances consider decision variables similar to the LRPTW without including time windows. The selected CLRP instances are coord20, coord50, coord100, and coord200, which were accessed at http://prodhonc.free.fr/Instances/instances_us.htm. The main data of these instances are:

- Number of depots: $m \in\{5,10\}$

- Number of clients: $n \in\{20,50,100,200\}$

- Fixed capacity of vehicles: $Q \in\{75,150\}$

- Capacity of depots $W$, which varies according to the instance.

A set of computational experiments are run on the chosen instances. The initial population size is set to 100. The initialization technique is a combination of a random approach for the shelters status string and a nearest neighbor heuristic for allocating and routing of the MPs. The mutation rate is $100 \%$, but in the case of no improvement in the mutated solution, the solution is not changed.

Each instance is run once with a fixed value of 100 iterations. The memetic algorithm is implemented in Matlab version R2012a, on an Intel ${ }^{\circledR}$ Core ${ }^{\mathrm{TM}}$ i5 processor with $8 \mathrm{~GB}$ of RAM.

A comparison is made between the results presented by Prodhon [47] and the solutions obtained with the proposed MA for the LRPTW. However, a direct comparison cannot be carried out since the Prodhon instances evaluate another objective function (total cost). The proposed MA for the LRPTW solution is not designed to calculate the costs of the routes; hence, the decision to compare the number of vehicles (buses) to be used and the number of open depots (shelters) was made. Table 1 presents the results obtained by the MA and the results found by Prodhon [47].

As shown in Table 1, most of the instances generate the same number of vehicles nbveh. However, there are considerable differences in costs $\mathbf{c d}$ and quantities of open deposits nbdep (shelters), which can be explained by the difference in the objective function. Since the LRPTW aims at minimizing the evacuation time, the cost of opening the depot (shelter) does not influence the response.

\section{Case Study}

In order to implement the proposed model, a case study is carried out in the city of Bucaramanga (Colombia) to locate emergency shelters and identify evacuation routes.

\section{A. Description of the case study}

The case study focuses on Bucaramanga, a city located in one of the most active seismic regions of Colombia. This region is called "Bucaramanga nest" because of the existence of an intermediate-depth seismic focus located at $50 \mathrm{~km}$ from the city [48]. This seismic nest is classified as one of the most seismic zones in the world.

\section{B. Potential shelters and meeting points}

The problem network has 111 nodes (shelters) composed of 84 educational centers, 17 green areas (parks and forest areas), and 10 sports areas (coliseums, stadiums and sports fields). These 111 nodes are geolocated on the Bucaramanga map by using Google Maps (Fig. 3). Based on the information presented in [49], the shelters are described according to their location (commune and neighborhood), their type,

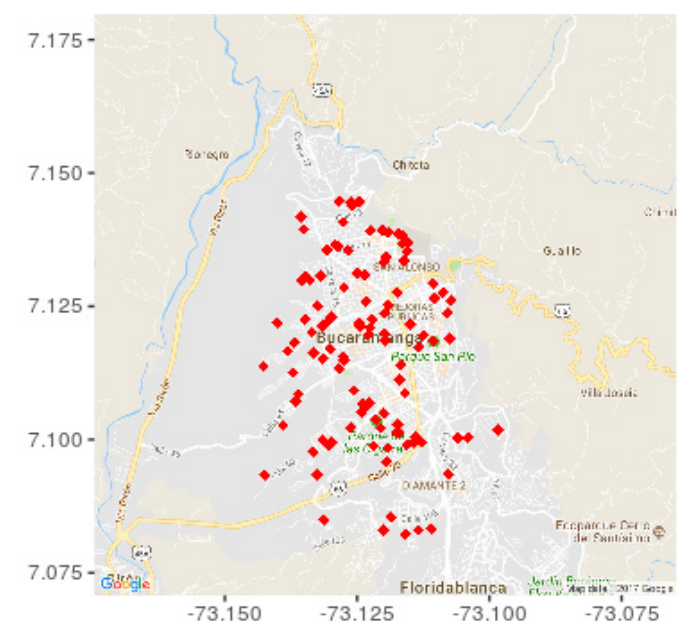

Fig. 3. Location of shelters in the political map of Bucaramanga. Source: Authors.

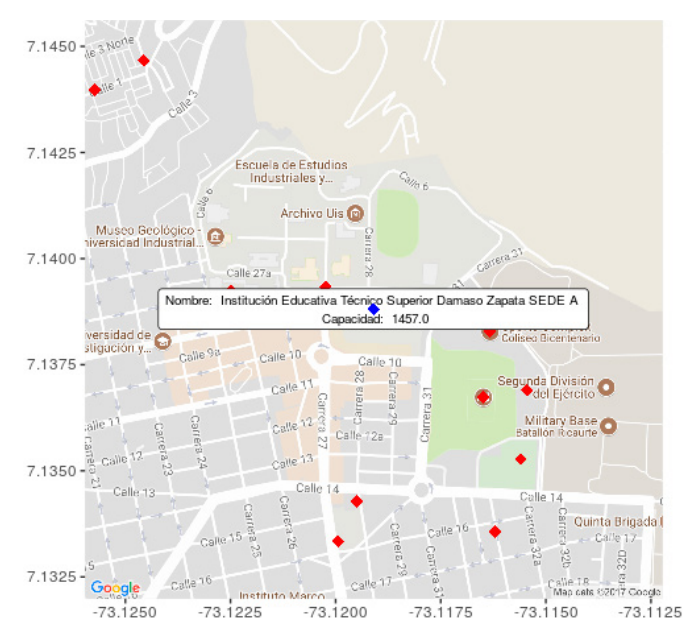

Fig. 4. Example of a temporary shelter profile. Source: Authors. 
their total area in square meters, and their capacity in number of people (see example in Fig. 4). The temporary shelters capacity is taken from [49], or it is calculated using the formulas presented in [49].

From the information on Bucaramanga seismic vulnerability presented by Maldonado and Chio in 2005 [50], three areas (communes) within the city would be more affected by different seismic intensities. These areas are Norte, Morrorico, and Cabecera. To estimate the number of meeting points and the number of people to be evacuated, the following parameters are taken into account:

- Inhabited area in each zone.

- Percentage of people affected or to be evacuated by commune.

- Number of people per square meter.

- Area that supplies a meeting point.

- Percentage of people to be evacuated in each period of time.
Regarding the percentage of people to be evacuated, we consider it is $30 \%, 75 \%$, and $50 \%$ for the Cabecera, Morrorrico, and Norte areas, respectively, based on the possible damages of the buildings [50]. Taking into account these percentages and the total inhabited area in each zone, the number of people to evacuate and the ratio of inhabitants per square meter were considered. Table 2 presents the data for each study area.

The coverage area of each MP is set by means of Google Maps API by selecting a group of census blocks. Areas composed of 4 or 5 blocks were chosen, so people can just walk a short distance and arrive as soon as possible to their assigned MP. In addition, the idea is that no more than 40 people will be grouped together in a single MP. A total of $113 \mathrm{MPs}$ are located in the study areas: 30 in Morrorrico, 54 in Norte, and 29 in Cabecera. Fig. 5 shows the location of the MPs in the three study areas.

Table 1. Results of the Algorithm Test.

\begin{tabular}{|c|c|c|c|c|c|c|c|}
\hline \multirow{2}{*}{ INSTANCE } & \multicolumn{3}{|c|}{ BKS } & \multicolumn{3}{|c|}{ MEMETIC ALGORITHM } & \multirow{2}{*}{ GAPS } \\
\hline & nbdep & nbveh & $\mathrm{cd}$ & nbdep & nbveh & cd & \\
\hline $20-5-1 a$ & 3 & 5 & 25549 & 3 & 5 & 28893 & -13.0885749 \\
\hline $20-5-1 b$ & 2 & 3 & 15497 & 3 & 3 & 33578 & -116.674195 \\
\hline $20-5-2 a$ & 3 & 5 & 24196 & 3 & 5 & 22769 & 5.89766904 \\
\hline $20-5-2 b$ & 2 & 3 & 13911 & 4 & 4 & 36499 & -162.375099 \\
\hline $50-5-1$ & 3 & 12 & 25442 & 4 & 12 & 39089 & -53.639651 \\
\hline $50-5-1 b$ & 2 & 6 & 15385 & 3 & 6 & 28733 & -86.759831 \\
\hline $50-5-2$ & 3 & 12 & 29319 & 4 & 12 & 41637 & -42.0137112 \\
\hline $50-5-2 b$ & 3 & 6 & 29319 & 3 & 6 & 35084 & -19.6630172 \\
\hline $50-5$-2bis & 3 & 12 & 19785 & 3 & 12 & 16928 & 14.4402325 \\
\hline 50-5-2bbis & 3 & 6 & 18763 & 3 & 6 & 19499 & -3.92261365 \\
\hline $50-5-3$ & 2 & 12 & 18961 & 3 & 12 & 37954 & -100.168767 \\
\hline $50-5-3 b$ & 2 & 6 & 18961 & 2 & 6 & 19416 & -2.39966247 \\
\hline $100-5-1$ & 3 & 24 & 132890 & 3 & 24 & 144012 & -8.36932802 \\
\hline $100-5-1 b$ & 3 & 11 & 132890 & 3 & 11 & 140196 & -5.49778012 \\
\hline $100-5-2$ & 2 & 24 & 102246 & 3 & 24 & 154994 & -51.5893042 \\
\hline $100-5-2 b$ & 2 & 11 & 102246 & 4 & 11 & 199356 & -94.9768206 \\
\hline $100-5-3$ & 2 & 24 & 88287 & 3 & 24 & 138923 & -57.3538573 \\
\hline $100-5-3 \mathrm{~b}$ & 2 & 11 & 88287 & 2 & 12 & 88287 & 0 \\
\hline $100-10-1$ & 3 & 26 & 154942 & 5 & 25 & 456065 & -194.345626 \\
\hline $100-10-1 b$ & 3 & 12 & 154942 & 6 & 11 & 312094 & -101.42634 \\
\hline $100-10-2$ & 3 & 25 & 154400 & 6 & 24 & 649460 & -320.634715 \\
\hline $100-10-2 b$ & 3 & 11 & 145956 & 6 & 11 & 691998 & -374.114117 \\
\hline $100-10-3$ & 3 & 24 & 139411 & 4 & 24 & 190336 & -36.5286814 \\
\hline $100-10-3 b$ & 3 & 11 & 139411 & 5 & 11 & 255951 & -83.5945514 \\
\hline $200-10-1$ & 3 & 47 & 253840 & 6 & 47 & 647736 & -155.174913 \\
\hline $200-10-1 b$ & 3 & 22 & 253840 & 6 & 22 & 610087 & -140.34313 \\
\hline 200-10-2 & 3 & 48 & 280370 & 6 & 48 & 677032 & -141.478047 \\
\hline $200-10-2 b$ & 3 & 22 & 280370 & 7 & 22 & 802192 & -186.119057 \\
\hline $200-10-3$ & 3 & 47 & 272528 & 4 & 47 & 391967 & -43.8263224 \\
\hline $200-10-3 b$ & 3 & 22 & 234660 & 5 & 20 & 474748 & -102.313134 \\
\hline
\end{tabular}

Source: Authors 


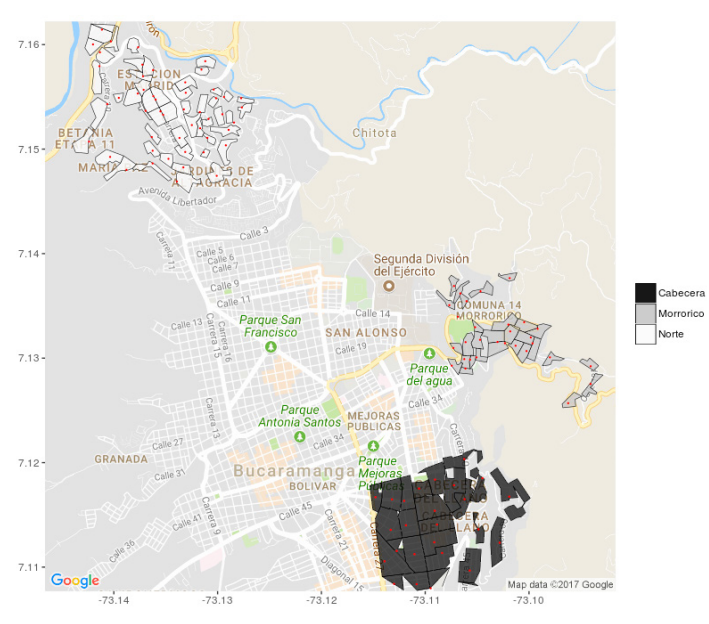

Fig. 5. Location of the MPs in the study areas. Source: Authors.

The case study also considers that all people within the coverage area of an MP do not reach it at the same time. They arrive in groups of $10 \%$ of the people assigned to this MP in a period of time $t$. Therefore, the bus must travel the same route several times before picking up $100 \%$ of the people. Besides, the demand of an MP is assigned to the same shelter. In summary, the case study is based on the construction of a route for a time $t$ that can be repeated $n$ times until satisfying $100 \%$ of the MP demand.

Table 2. Population and Area Relationship.

\begin{tabular}{|c|c|c|c|}
\hline AREA & CABECERA & NORTE & MORRORRICO \\
\hline $\begin{array}{c}\text { Total inhabitants } \\
\text { per commune }\end{array}$ & 33404 & 54183 & 22936 \\
\hline $\begin{array}{c}\% \text { of population } \\
\text { to evacuate }\end{array}$ & $30 \%$ & $50 \%$ & $75 \%$ \\
\hline $\begin{array}{c}\text { Population to } \\
\text { evacuate by } \\
\text { commune }\end{array}$ & 10022 & 27092 & 17202 \\
\hline $\begin{array}{c}\text { Total area per } \\
\text { commune (m }{ }^{2}\end{array}$ & 2670000 & 2290000 & 1280000 \\
\hline $\begin{array}{c}\text { Ratio } \\
\left.\text { (inhabitants } / \mathrm{m}^{2}\right)\end{array}$ & 0,003754 & 0,011830 & 0,013439 \\
\hline
\end{tabular}

Source: Authors.

We use the political map of Bucaramanga for the representation of the possible shelters and MPs using the Google Maps georeferencing tool, as shown in Fig. 5.

\section{Interpretation of time windows}

At the beginning, time windows (ai) of all MPs are equal to zero (0), since an emergency situation requires immediate attention. To close the hard time window, a parameter (bi) is established. It depends on the level of seismic vulnerability per commune. Based on Maldonado and Chio [50], a smaller closing time is assigned to the zone with greater vulnerability. In general, as the vulnerability level of the area decreases, the closing time increases. The planning horizon for evacuation and rescue operations within standard relief time in humanitarian logistics is 72 hours. Hence, our case study is focused on the first period of response time $t$, which represents $10 \%$ of the total time, that is, 7.2 hours.

The parameter (bi) for each zone is obtained by dividing the evacuation horizon (7.2 hours) into three parts, which represent the maximum times to perform the rescue operations in each zone simultaneously. The first part will be equal to the first third of the planning horizon rounded to the nearest whole value. Similarly, the second and third parts are calculated; however, this is carried out by accumulating the values to obtain a maximum time window equal to the planning horizon. Therefore, we established that the first segment of time will be equal to 3 hours ( $180 \mathrm{mins}$ ), the second to 5 hours (300 mins), and the third to 7 hours (420 mins) for the zones of Morrorrico, Norte and Cabecera, respectively.

\section{Disaster scenarios}

Considering the time windows criterion for each zone, two scenarios were simulate in order to evaluate the differences between homogeneous and random windows for each MP.

- Scenario 1: Homogeneous time windows. Start time ai $=0$ and closing time bi $=$ the maximum evacuation time per zone.

- Scenario 2: Random time windows. Start time ai = 0 and closing time bi $=$ a random number between ai and the maximum evacuation time per zone.

\section{E. Case study results}

An earthquake of intensity level VII (Mercalli scale) is considered for both scenarios. The proposed MA for LRPTW described in section 3 is applied to these scenarios. The algorithm calculates the number of shelters and the allocation of their MPs. It also provides the optimal routes for picking up people from the MPs to the shelters.

- Scenario 1: A number of 70 shelters is set up. The distribution is as follows: 56 educational centers, 10 green areas, and 4 sports areas. Each shelter serves 113 pre-established MPs. Since each shelter has a vehicle for picking up people, 70 buses are needed to evacuate the affected population. The total evacuation time for this scenario is 368 minutes (6 hours and 8 minutes), which is within the evacuation horizon of standard relief time. Fig. 6 shows the number of MPs per zone according to the type of shelter to which they were assigned.

- Scenario 2: The number of shelters to set up is 61 . They are distributed in 48 educational centers, 10 green areas, and 3 sports areas (Fig. 7). Hence, a number of 61 buses are required to pick up people affected by the earthquake. The total evacuation time for scenario 2 is slightly lower than for scenario 1 , that is, 365 minutes ( 6 hours and 5 minutes). 


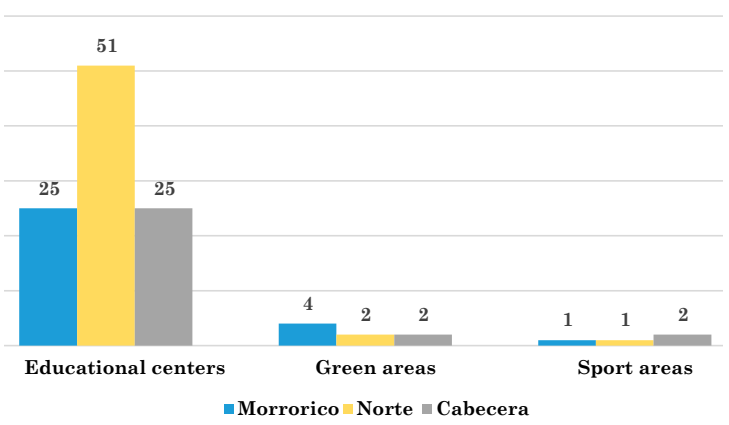

Fig 6. MPs according to the types of shelter and area (Scenario 1)

Source: Authors.

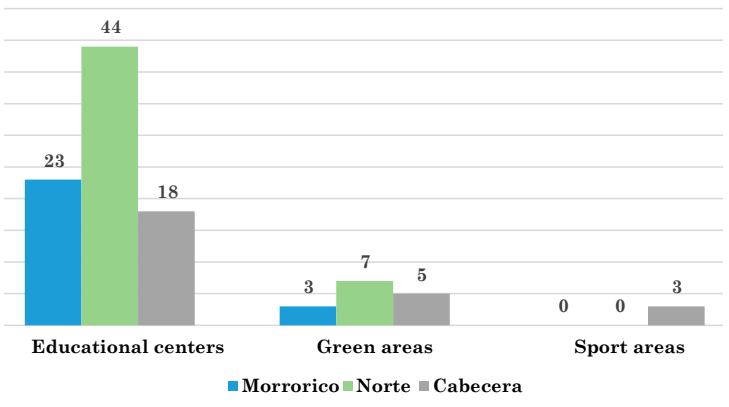

Fig. 7. MPs according to the types of shelter and area (Scenario 2)

Source: Authors.

\section{CONCLUSIONS}

This research seeks to solve the problem of locating shelters and building evacuation routes to facilitate humanitarian logistics operations after a seismic disaster. It also contributes to current studies on the application of operations research techniques in evacuation planning. To do so, the problem is modeled through an LRPTW with shelters as depots, meeting points as clients, buses as collection vehicles, and the attention time of affected people as time windows. This contribution includes the development of a memetic algorithm for the solution of the proposed model that allows to solve real-size instances. The hybrid initialization of the MA prevents early convergence by combining randomness and a heuristic technique. The performance of the proposed algorithm is evaluated through CLRP instances taken from the literature. Computational results indicate that the MA is a viable approach for the LRPTW solution.

Likewise, a case study is presented for the city of Bucaramanga in order to validate the proposed model with regard to the location of shelters and evacuation routes. For this, two scenarios are simulated.
They evidence the influence of the time windows treatment (homogeneous or random) on the objective function. This work also gives a framework for planning evacuation activities in a disastrous event for a real instance. Furthermore, this framework could be an initial work that allows the research team to develop a decision support tool for preparation activities in a disaster context in the city of Bucaramanga in a near future.

From a practical perspective, the location-routing problem must consider other criteria such as the evacuation cost -including the attention delay cost (victims cost) - and the cost of opening shelters and routing. In addition, the problem can include a split delivery approach where people from the same meeting point can be assigned to different shelters. The problem can also consider the constraint of opening shelters to a minimum occupancy rate. Finally, the model can be extended to the use of heterogeneous transport fleets, and the treatment of different types of clients and depots, such as hospitals or other actors with special considerations in the evacuation process.

\section{FundING}

This research was funded by Universidad Industrial de Santander through the project 1806 entitled: "A framework for the management of natural catastrophe emergency response systems through the location-routing problem with soft time windows LPRTW." This work was developed by the research group OPALO. Starting year: 2015. Ending year: 2016.

\section{REFERENCES}

[1] EM-DAT The International Disaster Database, "Centre for Research on the Epidemiology of Disasters-CRED." [Online]. Available: http://www.emdat.be/.

[2] J. Holguín-Veras, M. Jaller, L. N. Van Wassenhove, N. Pérez, and T. Wachtendorf, "On the unique features of post-disaster humanitarian logistics," J. Oper. Manag., vol. 30, no. 7-8, pp. 494-506, 2012. https://doi. org/10.1016/j.jom.2012.08.003

[3] FEMA, "Guide for All-Hazard Emergency Operations Planning," 1996.

[4] N. Altay and W. G. Green, "OR/MS research in disaster operations management," Eur. J. Oper. Res., vol. 175, no. 1, pp. 475-493, 2006. https://doi.org/10.1016/j. ejor.2005.05.016

[5] A. M. Anaya-Arenas, J. Renaud, and A. Ruiz, "Relief distribution networks: a systematic review," Ann. Oper. Res., no. April, pp. 53-79, 2014. https://doi.org/10.1007/ s10479-014-1581-y

[6] G. Galindo and R. Batta, "Review of recent developments in OR/MS research in disaster operations management," Eur. J. Oper. Res., vol. 230, no. 2, pp. 201211, 2013. https://doi.org/10.1016/j.ejor.2013.01.039

[7] G. Kovács and K. M. Spens, "Humanitarian logistics in disaster relief operations," Int. J. Phys. Distrib. Logist. Manag., vol. 37, no. 2, pp. 99-114, 2007. https://doi. org/10.1108/09600030710734820 
[8] N. C. Simpson and P. G. Hancock, "Fifty Years of Operational Research and Emergency Response," J. Oper. Res. Soc., vol. 60, pp. s126-s139, 2009. https://doi. org/10.1057/jors. 2009.3

[9] L. E. De la Torre, I. S. Dolinskaya, and K. R. Smilowitz, "Disaster relief routing: Integrating research and practice," Socioecon. Plann. Sci., vol. 46, no. 1, pp. 88-97, 2012. https://doi.org/10.1016/j.seps.2011.06.001

[10] A. M. Caunhye, X. Nie, and S. Pokharel, "Optimization models in emergency logistics: A literature review," Socioecon. Plann. Sci., vol. 46, no. 1, pp. 4-13, 2012. https://doi.org/10.1016/j.seps.2011.04.004

[11] T. Yamada, "A network flow approach to a city emergency evacuation planning," Int. J. Syst. Sci., vol. 27, no. 10, pp. 931-936, Oct. 1996. https://doi. org $/ 10.1080 / 00207729608929296$

[12] Q. Lu, B. George, and S. Shekhar, "Capacity Constrained Routing Algorithms for Evacuation Planning: A Summary of Results," Springer, Berlin, Heidelberg, 2005, pp. 291-307.

[13] Y. -C. Chiu, H. Zheng, J. Villalobos, and B. Gautam, "Modeling no-notice mass evacuation using a dynamic traffic flow optimization model," IIE Trans., vol. 39, no. 1, pp. 83-94, Jan. 2007. https://doi. org/10.1080/07408170600946473

[14] F. Sayyady and S. D. Eksioglu, "Optimizing the use of public transit system during no-notice evacuation of urban areas," Comput. Ind. Eng., vol. 59, no. 4, pp. 488-495, Nov. 2010. https://doi.org/10.1016/j. cie.2010.06.001

[15] D. R. Bish, "Planning for a bus-based evacuation," $O R$ Spectr., vol. 33, no. 3, pp. 629-654, 2011. https://doi. org/10.1007/s00291-011-0256-1

[16] M. Goerigk, B. Grün, and P. Heßler, "Branch and bound algorithms for the bus evacuation problem," Comput. Oper. Res., vol. 40, no. 12, pp. 3010-3020, 2013. https:// doi.org/10.1016/j.cor.2013.07.006

[17] D. R. Bish, H. D. Sherali, and A. G. Hobeika, "Optimal evacuation planning using staging and routing," J. Oper. Res. Soc., vol. 65, no. 1, pp. 124-140, 2014. https://doi.org/10.1057/jors.2013.3

[18] M. Goerigk and B. Grün, "A robust bus evacuation model with delayed scenario information," OR Spectr., vol. 36, no. 4, pp. 923-948, Oct. 2014. https://doi. org/10.1007/s00291-014-0365-8

[19] M. Goerigk, B. Grün, and P. Heßler, "Combining bus evacuation with location decisions: A branch-and-price approach," Transp. Res. Procedia, vol. 2, pp. 783-791, 2014. https://doi.org/10.1016/j.trpro.2014.09.088

[20] S. Salhi and G. K. Rand, "The effect of ignoring routes when locating depots," Eur. J. Oper. Res., vol. 39, no. 2, pp. 150-156, Mar. 1989. https://doi.org/10.1016/03772217(89) $90188-4$

[21] M. Drexl and M. Schneider, "A Survey of the Standard Location-Routing Problem," 2014.

[22] H. Min, V. Jayaraman, and R. Srivastava, "Combined location-routing problems: A synthesis and future research directions," Eur. J. Oper. Res., vol. 108, no. 1, pp. 1-15, 1998. https://doi.org/10.1016/S03772217(97)00172-0

[23] G. Nagy and S. Salhi, "Location-routing: Issues, models and methods," Eur. J. Oper. Res., vol. 177, no. 2, pp. 649-672, Mar. 2007. https://doi.org/10.1016/j. ejor.2006.04.004

[24] C. Prodhon and C. Prins, "A survey of recent research on location-routing problems," Eur. J. Oper. Res., vol. 238, no. 1, pp. 1-17, Oct. 2014. https://doi.org/10.1016/j. ejor.2014.01.005
[25] K. Govindan, a. Jafarian, R. Khodaverdi, and K. Devika, "Two-echelon multiple-vehicle location-routing problem with time windows for optimization of sustainable supply chain network of perishable food," Int. J. Prod. Econ., vol. 152, pp. 9-28, Jun. 2014. https://doi. org/10.1016/j.ijpe.2013.12.028

[26] A. Ceselli, G. Righini, and E. Tresoldi, "Combined location and routing problems for drug distribution," Discret. Appl. Math., vol. 165, pp. 130-145, Mar. 2014. https://doi.org/10.1016/j.dam.2013.07.016

[27] R. Caballero, M. González, F. M. Guerrero, J. Molina, and C. Paralera, "Solving a multiobjective location routing problem with a metaheuristic based on tabu search. Application to a real case in Andalusia," Eur. J. Oper. Res., vol. 177, no. 3, pp. 1751-1763, Mar. 2007. https://doi.org/10.1016/j.ejor.2005.10.017

[28] S. Alumur and B. Y. Kara, "A new model for the hazardous waste location-routing problem," Comput. Oper. Res., vol. 34, no. 5, pp. 1406-1423, 2007. https://doi. org/10.1016/j.cor.2005.06.012

[29] J. Ahn, O. de Weck, Y. Geng, and D. Klabjan, "Column generation based heuristics for a generalized location routing problem with profits arising in space exploration," Eur. J. Oper. Res., vol. 223, no. 1, pp. 47-59, Nov. 2012. https://doi.org/10.1016/j.ejor.2012.06.018

[30] W. Yi and L. Özdamar, "A dynamic logistics coordination model for evacuation and support in disaster response activities," Eur. J. Oper. Res., vol. 179, no. 3, pp. 1177-1193, Jun. 2007. https://doi.org/10.1016/j. ejor.2005.03.077

[31] S. Li and H. Zhou, "Optimization model of fuzzy location-routing problem of victim search in flood disaster," J. Chem. Pharm. Res., vol. 6, no. 6, pp. 2080-2085, 2014.

[32] A. Pramudita, E. Taniguchi, and A. Qureshi, "Location and Routing Problems of Debris Collection Operation after Disasters with Realistic Case Study," Procedia . Soc. Behav. Sci., vol. 125, pp. 1-15, 2014. https://doi. org/10.1016/j.sbspro.2014.01.1487

[33] S. V. Ukkusuri and W. F. Yushimito, "Location Routing Approach for the Humanitarian Prepositioning Problem," Transp. Res. Rec. J. Transp. Res. Board, vol. 2089 no. 1, pp. 18-25, 2009. https://doi.org/10.3141/2089-03

[34] R. Tavakkoli-Moghaddam, a. Makui, and Z. Mazloomi, "A new integrated mathematical model for a bi-objective multi-depot location-routing problem solved by a multi-objective scatter search algorithm," J. Manuf. Syst., vol. 29, no. 2-3, pp. 111-119, 2010. https://doi. org/10.1016/j.jmsy.2010.11.005

[35] Z. Mingang, C. Zengshou, and W. Xiaoyan, "Research on location-routing problem of relief system based on emergency logistics," in Industrial Engineering and Engineering Management, 2009. IE\&EM'09. 16th International Conference on, 2009, pp. 228-232. https:/ doi.org/10.1109/ICIEEM.2009.5344599

[36] S. Li, Z. Ma, and B. Zheng, "Dynamic multi-objective location-routing problem in post-earthquake logistics system," J. Chem. Pharm. Res., vol. 6, no. 6, pp. 15151520,2014

[37] S. Hua-li, W. Xun-qing, and X. Yao-feng, "A Bi-level Programming Model for a Multi-facility LocationRouting Problem in Urban Emergency System," in Engineering Education and Management, Springer Berlin Heidelberg, 2012, pp. 75-80.

[38] L. Alçada-Almeida, L. Tralhão, L. Santos, and J. Coutinho-Rodrigues, "A multiobjective approach to locate emergency shelters and identify evacuation routes in urban areas," Geogr. Anal., vol. 41, no. 1, pp. 9-29, 2009. https://doi.org/10.1111/j.1538-4632.2009.00745.x 
[39] J. Coutinho-Rodrigues, L. Tralhão, and L. AlçadaAlmeida, "Solving a location-routing problem with a multiobjective approach: the design of urban evacuation plans," J. Transp. ..., vol. 22, pp. 206-218, May 2012. https://doi.org/10.1016/j.jtrangeo.2012.01.006

[40] M. Goerigk, K. Deghdak, and P. Heßler, "A comprehensive evacuation planning model and genetic solution algorithm," Transp. Res. Part E Logist. Transp. Rev., vol. 71, pp. 82-97, 2014.

[41] E. Nikbakhsh and S. H. Zegordi, "A Heuristic Algorithm and a Lower Bound for the Two-Echelon Location-Routing Problem with Soft Time Window Constraints," vol. 17, no. 1, pp. 36-47, 2010.

[42] H. I. Gündüz, "The Single-Stage Location-Routing Problem with Time Windows," pp. 44-58, 2011. https:// doi.org/10.1007/978-3-642-24264-9_4

[43] M. H. Fazel Zarandi, A. Hemmati, S. Davari, and I. Burhan Turksen, "Capacitated location-routing problem with time windows under uncertainty," Knowledge-Based Syst., vol. 37, pp. 480-489, Jan. 2013. https://doi.org/10.1016/j.knosys.2012.09.007

[44] R. Song, S. He, and L. Zhang, "Optimum Transit Operations during the Emergency Evacuations," J. Transp. Syst. Eng. Inf. Technol., vol. 9, no. 6, pp. 154-160, Dec. 2009. https://doi.org/10.1016/S1570. 6672(08)60096-3

[45] L. Zhu, D. Hu, X. Wei, and X. Chen, "Solving the LRPTW Based on Tabu Search Algorithm," in ICLEM 2014, 2014, pp. 904-909.

[46] I. Karaoglan and F. Altiparmak, "A memetic algorithm for the capacitated location-routing problem with mixed backhauls," Comput. Oper. Res., vol. 55, pp. 200-216, 2014. https://doi.org/10.1016/j.cor.2014.06.009

[47] C. Prodhon, "Le Problème de Localisation-Routage," 2006.

[48] C. E. Coral-Gomez, "La convergencia de placas en el noroccidente Suramenricao y el origen del nido de bu caramanga," Rev. Acad. Colomb. Ciencias Exactas, $\mathrm{Fl}$ sicas y Nat., vol. 17, no. 66, pp. 521-529, 1990.

[49] A. Barrera Navarro and A. Gomez Hernandez, "Un algoritmo evolutivo para el problema de distribución de recursos post-desastres sísmicos en la ciudad de Bucaramanga.," Universidad Industrial de Santander, 2016.

[50] E. Maldonado and G. Chio, "Identificación de las zonas sísmicas más vulnerables en la ciudad de Bucaramanga,” UIS Ing., vol. 4, no. 2, pp. 99-116, 2005.
Henry Lamos Díaz graduated in PhD. in Mathematical Physics in 1997 from Moscow State University (LOMONOSOV), Russia; MSc in Informatics in 1990 from the Industrial University of Santander, Colombia; MSc. in Mathematics in 1982 from the University of Friendship, Moscow, Russia, and Mathematics in 1981 from the University of Friendship, Moscow, Russia. He is a research professor at OPALO Research Group. He is a member of the Colombian Association of Operations Research ASOCIO and an associated professor at the Industrial University of Santander in which he is also adjunct professor in the School of Industrial and Business Studies. https://orcid.org/00000003-1778-9768

Karin Aguilar Imitola received the title of MSc in Industrial Engineering and of Industrial Engineer from the Industrial University of Santander. Member of the OPALO Research group and adjunct professor to the School of Industrial and Business Studies. Her research interests include research applications of operations in humanitarian logistics, optimization and vehicle routing. http://orcid.org/0000-0001-9776-4258

Melissa Barreto received the title of Industrial Engineer from the Industrial University of Santander (Bucaramanga, Colombia) in 2016. Her research interests include operations research, optimization, metaheuristics, production planning and programming. Currently, she is a project analyst at Penagos Hermanos y Cía S.A.S. http://orcid.org/0000-00025365-6113

Paula N. Niño received the title of Industrial Engineer from the Industrial University of Santander (Bucaramanga, Colombia). Her research interests include operations research, optimization, metaheuristics, production planning and programming. http://orcid. org/0000-0002-5638-0853

Daniel Orlando Martínez-Quezada received his Master's degree in Industrial Engineering in 2017 and his Industrial Engineering degree in 2014, both from the Industrial University of Santander, Colombia. Currently, he is a professor affiliated to the OPALO research group, and an adjunct professor in the School of Industrial and Business Studies of the Industrial University of Santander. http://orcid.org/0000-00029910-1770 